\title{
Yağlık Ayçiçeği Tanelerinin Bazı Karakteristik Özelliklerinin Belirlenmesi
}

\author{
Volkan GÜL ${ }^{1}$ Erdoğan ÖZTÜRK ${ }^{2^{*}}$ Tașkın POLAT ${ }^{2}$ \\ ${ }^{1}$ Bayburt Üniversitesi, Uygulamalı Bilimler Meslek Yüksekokulu, Bayburt \\ ${ }^{2}$ Atatürk Üniversitesi Ziraat Fakültesi Tarla Bitkileri Bölümü, 25100, Erzurum \\ (*Sorumlu yazar e-mail: erozturk@ atauni.edu.tr)
}

Geliş Tarihi :31.05.2017

Kabul Tarihi : 19.07.2017

\begin{abstract}
ÖZET: Ayçiçeği tane özellikleri, verim ve kaliteyle yakından alakalıdır. Dolayısıyla, bu özellikler, genotip ve çevrenin ortak etkileşimi altında olup, özellikle iklim ve toprak yapısı gibi faktörlerden etkilenmektedir. Bu araştırmada, Orta Karadeniz Bölgesinde yağlık ayçiçeği tarımının yoğunluğu dikkate alınarak seçilen, Samsun (Bafra, Vezirköprü ve Havza), Amasya (Merzifon), Corum (Merkez) ve Tokat (Turhal) yörelerinde 2015 yılında üretici bazında yetiștiriciliği yapılan ve pazara sunulan yağlık ayçiçeği tanelerinin boyu, eni, kalınlığı, bin tane ağırlığı, tane iç oranı, kabuk oranı, nem ve yağ oranları incelenmiştir. Çalışmada, farklı yörelerde yetiştirilen yağlık ayçiçeği tanelerinde nem oranı haricindeki diğer özellikler bakımından önemli farklılıklar tespit edilmiştir. Araştırma sonuçlarına göre; ortalama tane boyu, eni ve kalınlığı sırasıyla 10.6-11.4; 4.9-5.4 ve 2.6-3.3 $\mathrm{mm}$, kabuk oranı \%12.7-26.1, bin tane ağırlı̆̆ $49.0-65.0 \mathrm{~g}$, tane iç oranı \%58.7-77.5, nem içeriği \% 7.0-8.7 ve yağ oranı \%41.5745.67 arasında değerler almıştır. Bu sonuçlara göre, bölgede Samsun-Bafra ve Tokat-Turhal yörelerinde üretilen yağlık ayçiçeği taneleri incelenen özellikler yönünden ön plana çıkmıştır.
\end{abstract}

Anahtar kelimeler: Orta Karadeniz Bölgesi, yağlık ayçiçeği, tane özellik, üretici

\section{Determination of Some Characteristics Properties of Oil Sunflower Seed}

\begin{abstract}
Sunflower seed properties are closely related to yield and quality. Therefore, these properties are under the common interaction of genotype and environment, especially affected by factors such as climate and soil structure. The parameters were examined length, width, thickness, 1000-seed weight, the ratio of dehulled/hulledseed weight, ratio of peel, moisture content and oil content of oil sunflower seeds, obtained from commonly oil sunflower produced locations, Samsun (Bafra, Vezirköprü and Havza), Amasya (Merzifon), Çorum (Center) and Tokat (Turhal), in Central Black Sea Region in 2015 year. The average length, width, thickness, ratio of hull, 1000-seed weight, the ratio of dehulled/hulledseed weight, moisture content and oil content ranged from 10.6 to $11.4,4.9$ to $5.4,2.6$ to $3.3 \mathrm{~mm}, 12.7$ to $26.1 \%, 49.0$ to $65.0 \mathrm{~g}, 58.7-77.5 \%, 7.0-8.7 \%$ and $41.57-45.67 \%$, respectively. According to these results, oil sunflower seeds produced in Samsun-Bafra and Tokat-Turhal locations of the region were found to be better than oil sunflower seeds produced in the other locations in terms of the investigated properties.
\end{abstract}

Keywords: Central Black Sea Region, oil sunflower, seed property, producer

\section{GíRIS}

Gıda amaçlı kullanılan yağlı tohumlu bitkilerde, yağ üretimi ön plana çıkmaktadır. Aynı zamanda, un ve diğer gidalara katkı maddesi olarak da bu bitkilerden faydalanılmaktadır. Ayrıca, bu ürünler işlendikten sonra kalan atıklar da yem hammaddesi veya katkısı olarak da değerlendirilmektedir. Ülkemizde tarımı yapılan yağlı tohumlu bitkiler; ayçiçeği, çiğit, soya, yerfıstığ 1 , haşhaş, susam, kolza ve aspirdir. Ayçiçeği, adaptasyon kabiliyetinin yüksek oluşu nedeniyle yurdumuzun birçok yöresinde yetiştirilebilen, tanelerinde yüksek oranda (\% 22-55) ve kaliteli yağ [doymamış yağ oranı $\% 69$ (Linoleik asit \%50-65, Oleik asit \%25-35)] içeren bitkisel ham yağ üretimi bakımından önemli bir yă̆ bitkisidir. Kuraklığa ve düşük sıcaklıklara dayanıklı olması, çeşitli toprak tiplerine ve çok farklı çevreye adapte olması gibi özelliklerinden dolayı ülkemizde üretilen yağlı tohumlu bitkiler içerisinde ilk sırayı almaktadır (Atakişi, 1985; Arığlu vd., 2010).

Türkiye'de yağlık ayçiçeği ekimi ortalama 505 bin hektar seviyelerindedir. Üretim alanları bakımından ağırlıklı olarak Trakya Bölgesinde artış olur iken, özellikle Karadeniz Bölgesi'nde 50 bin hektardan 35 hektara düşmüştür (Anonim, 2016a). Yağlı ayçiçeği en fazla Trakya-Marmara Bölgesinde (\%47.2) üretilmekte olup, Ülkemizde geriye kalan ayçiçeği üretiminin ise \%29.2'si Orta Anadolu Bölgesinde, \%12'si Karadeniz, \%8.7'si Akdeniz, \%2.8'i Doğu ve Güneydoğu Anadolu Bölgelerinde yapılmaktadır (Anonim, 2015).

Ayçiçeği yetiştiriciliğinde bölgeye uygun çeşit kullanımı, diğer kültür bitkilerinde olduğu gibi verimi ve kaliteyi artıran temel unsurlardandır. Bitkinin yabancı döllenme özelliği ve yetiştiricilikle ilgili olarak karşılaşılan birçok sorun nedeniyle, kaliteli ve yağ oranı yüksek tohum üretimi önem arz etmektedir. Diğer taraftan, istenilen kalitede ayçiçeği tanesi üretiminin gerçekleştirilmesinde ki başarı, uygun tohumluğun kullanılmasının yanı sıra, uygun yetiştirme tekniklerinin uygulanmasını da gerektirmektedir. Dolayisıyla üretilen bitkiden alınacak verim; genotip ve çevrenin ortak etkileşimi altında olup, özellikle iklim ve toprak yapısı gibi faktörlerden etkilenmektedir. 
Ayçiçeği tanelerinin uzunluk, en ve kalınlıkları ile tane iç oranı ve bin tane ağırlığ 1 gibi özellikler, bir çeşidin tanımlanmasında ve bitki yetiştiriciliğinde elde edilen verimle yakından ilgilidir. Çeşitler arasında bu özellikler değişik varyasyonlar göstermekte olup, Fick (1978) tane uzunluklarının 6$25 \mathrm{~mm}$, geniş̧liklerinin 3-13 mm, İncekara (1973) ise tane boyunun 7-20 $\mathrm{mm}$, eninin $5-15 \mathrm{~mm}$ ve kalınlığının 3-7 $\mathrm{mm}$ arasında değiştiğini belirtmişlerdir. Ayrıca, ayçiçeği tanesinde kabuk oranının az, tane iç oranının yüksek olması istenen bir özelliktir. Yazıcıŏglu ve Karaali (1983), yağlık ayçiçeği tanelerinin kabuk oranının \%26-35, iç oranının \%65-74 ve nem oranının \%6-11 arasında değiştiğini belirlemiş̧lerdir. Yine, yağlık ayçiçeği çeşitlerinin tanelerinde belirlenen ortalama tane uzunluğunun 1.14-1.12 cm, tane genişliğinin 0.49$0.51 \mathrm{~cm}$, bin tane ağırlığının 57.26-62.28 g ve kabuk oranının \%21.54-23.32 olduğu belirtilmiştir (Bayrak ve Bayraktar 1995).

Yağlık ayçiçeği tanelerinin özelliklerinin araştırıldığı benzer çalışmalarda, Coşge (2007) tohum uzunluğunun 10.9-14.1 mm, genişliğinin 5.1$7.2 \mathrm{~mm}$, bin tane ağırlığının 75.1-103.2 g; Özgödek (1993) ise tane uzunluğunun 14.1-28.0 mm, genişliğinin 6.2-8.3 mm, bin tane ağırlığının 69.7$183.3 \mathrm{~g}$ ve iç oranının \%46.2-57 arasında değiştiğini bildirmişlerdir. Gupta ve Das (1997), ayçiçeği tohumunun ortalama uzunluk, genişlik ve kalınlık değerleri ile nem oranını sırasıyla, $9.52 \mathrm{~mm}, 5.12$ $\mathrm{mm}, 3.27 \mathrm{~mm}$ ve \% 6.2 olarak tespit etmişlerdir. Jafari vd. (2011) ortalama tane uzunluğunu, genişliğini ve kalınlığının sırasıyla 14.32-31.00, 4.73-9.82 ve 2.36-6.67 $\mathrm{mm}$ arasında değiştiğini bulmuştur. Oraki vd. (2011) kullanılan hibrit ayçiçeği tanelerinin uzunluğunun 6.36-12.87 mm, genişliğinin 2.54-7.57 ve kalınlıklarının 2.03-5.52 $\mathrm{mm}$ arasında değerler aldığını bildirmişlerdir. Yine, Duca ve Glijın (2013), tane uzunluğunun 9.6-12.1 mm, genişliğinin 4.5-5.9 mm ve kalınlığının 3.1-3.8 mm; Kara (1991) tane iç oranının \%61.9-71.9 ve bin tane ağırlığının 50.4-64.2 g; bin tane ağırlığının Demir (2009) 42,4766,23 g ve Doğan (2010) 25.43-44.56 g; Karaaslan vd. (2007), tane iç oranının \%55.47-74.83 arasında değiştiğini belirtmişlerdir. Seifi ve Alimardani (2010) ayçiçeği tanelerin uzunluk, genişlik ve kalınlıkların 12.14-12.57, 5.79-6.38 ve 3.86-4.09 $\mathrm{mm}$, bin tane ağırlıklarının 80.3-96.8 g ve tane iç oranlarının \%422 arasında değişen değerler aldığını saptamışlardır. Çiftçi koşullarında üretilen yağlık ayçiçeği tanelerinde en yüksek \%41.30 oranında yağ içeriği tespit edilmiştir (Tunçtürk vd., 2005). Çil vd. (2011), değişik lokasyonlarda kullanılan ayçiçeği çeşitlerine bağlı olarak en yüksek yağ içeriklerini $\% 46.1$ ve $\% 47.6$ oranında belirlemişlerdir.

Bu çalışmada da, Orta Karadeniz Bölgesi'nde yetiştiriciliği yapılan ve bölgedeki pazarlardan temin edilen yağlık ayçiçeği tohumlarına ait genel karakteristik özelliklerinin belirlenmesi, daha sonraki dönemlerde yapılacak çalışmalara yardımcı olunabilmesi amaçlanmıştır.

\section{MATERYAL VE METOT}

Araştırma, Orta Karadeniz Bölgesinde yağlık ayçiçeği tarımının yoğunluğu dikkate alınarak seçilen, Samsun'da Bafra, Vezirköprü ve Havza, Amasya'da Merzifon, Çorum'da Merkez ve Tokat'ta Turhal ilçelerinde 2015 y1lında yürütülmüştür. Samsun genellikle 1lıman bir iklime sahiptir. Ancak sahil şeridinde iç kesimlerde iklim iki ayrı özellik gösterir. Bafra ilçesinde Karadeniz ikliminin etkileri görülür. Yazlar sıcak, kışlar ılık ve yağışlı geçer. Y1llık ortalama sıcaklığı $13.6{ }^{0} \mathrm{C}$, y1llık ortalama yağış miktarı da $730 \mathrm{~mm}$ 'dir. Vezirköprü ve Havza ilçeleri yüksekliği 2000 m’yi bulan Akdağ ve 1500 m'yi bulan Canik Dağlarının etkisi altında kalır. Burada dağların etkisinden kışlar soğuk, yağmur ve kar yağışlı, yazlar ise serin geçer. Vezirköprü ilinin yıllık ortalama sıcaklığı $12.9^{\circ} \mathrm{C}$, yıllık ortalama yağış miktarı $512 \mathrm{~mm}$ olurken, Havza'da yıllık ortalama sıcaklığı $11.5{ }^{0} \mathrm{C}$, yıllık ortalama yağış miktarı ise $448 \mathrm{~mm}$ olarak kaydedilmiştir. Amasya ili Merzifon ilçesinde sıcak ve 1lıman bir iklim hakimdir. Kış aylarında yaz aylarından çok daha fazla yağış düşmektedir. Merzifon ilinin yıllık ortalama sıcaklığı 11.5 ${ }^{0} \mathrm{C}$, yıllık ortalama yağ 1 ş miktarı ise 418 mm'dir. Çorum, genel olarak yazları sıcak ve kurak, kışları soğuk ve yağışlıdır. Kuzeyden güneye doğru gidildikçe iklim sertleşir. En fazla yağış mayıs ayında düşer. Yıllık ortalama sıcaklığı $10.8{ }^{0} \mathrm{C}$, yıllık ortalama yağış miktarı $433 \mathrm{~mm}$ civarındadır. Tokat ili Turhal ilçesi genelde 1lıman bir iklime sahiptir. Yillık ortalama sıcaklığı $12.7{ }^{0} \mathrm{C}$, yıllık ortalama yağış miktarı 440 mm'dir (Anonim, 2016b).

Çalışmada materyal olarak, belirtilen il ve ilçelerde üretici bazında sulu şartlarda yetiştiriciliği yapılan ve pazara sunulan yağlık ayçiçeği tanelerine ait örnekler kullanılmıştır. Bölge üreticileri tarafından ise daha çok Bosfora, Coral, Sanbro, Sonay, L65590 ve 64LL82 hibrit yağlık ayçiçeği çeşitlerinin kullanıldı̆̆ tarafından yetiştirilen ve pazara sunulan bu ayçiçeği çeşitlerinden alınan 500 g'lık örnekler ölçüm, tartım ve analizleri yapılmak üzere laboratuvar şartlarına getirilmiştir. Tohum örneklerinde bin tane ağırlığı, tane iç, nem ve kabuk oranları ile, tane uzunluğu, kalınlığı ve tane genişliği gibi karakterler incelenmiştir. Tane boyu, genişliği ve kalınlığ kumpasla ölçülerek belirlenmiş; tane iç oranı, "tane iç oranı = iç ağırlığı (g) / kabuklu ağırlık (g) x 100" ve tane nem oran 1 " $\%$ nem $=100-\%$ kuru madde" formüllerine göre" hesaplanmıştır. Kabuk oranı, kabuklu olarak tartılan tanenin iç ve kabuğu ayrılarak, kabuk ağırlığının tohum ağırlığına 
oranlanması şeklinde; tane yağ oranı, Soxhelet Metodu kullanılarak ve bin tane ağırlığı ise $4 \times 100$ adet tohum sayılarak tartılmış, ortalama değerler 10 ile çarpılarak bulunmuştur.

Elde edilen sonuçlar "Tesadüf Parselleri" deneme desenine göre dört tekerrürlü olarak analiz edilmişlerdir. Araştırma sonucunda elde edilen veriler SPSS bilgisayar programı yardımıyla varyans analizine tabi tutulmuş ve ortalamalar arasındaki farklılıklar DUNCAN çoklu karşılaştırma testi ile tespit edilmiştir.

\section{BULGULAR VE TARTISSMA}

Orta Karadeniz Bölgesinde tarımı yapılan yağlık ayçiçeği tanelerinde incelenen özelliklere ait ortalama değerler ve varyans analizi sonuçları Çizelge 1'de verilmiştir. Elde edilen sonuçlara göre bölgesel bazda temin edilen taneler arasinda tane boyu ve iç oranı bakımından $\mathrm{p}<0.05$, tane eni ve kalınlığı ile kabuk oranı, bin tane ağırlığı ve yağ oranı yönünden ise $p<0.01$ seviyesinde istatistiksel olarak önemlilik tespit edilmiştir. Diğer taraftan, nem oranı bakımından farklı yörelerde yetiştirilen yağlık ayçiçeği tanelerinde ise önemlilik belirlenmemiştir.

Çizelge 1. Orta Karadeniz bölgesinde yağlık ayçiçeği yetiştiriciliği yapılan il ve ilçelerden temin edilen yağlık ayçiçeği tanelerinde belirlenen karakteristik özelliklere ait değerler

\begin{tabular}{|c|c|c|c|c|c|c|c|c|c|c|}
\hline \multicolumn{3}{|c|}{$\begin{array}{c}\text { Yağlık Ayçiçeği Üretici } \\
\text { Bölgeler }\end{array}$} & $\begin{array}{l}\text { Tane } \\
\text { Boyu } \\
(\mathbf{m m})\end{array}$ & $\begin{array}{l}\text { Tane } \\
\text { Eni } \\
(\mathbf{m m})\end{array}$ & $\begin{array}{c}\text { Tane } \\
\text { Kalınlığı } \\
(\mathbf{m m})\end{array}$ & $\begin{array}{c}\text { Kabuk } \\
\text { Oranı } \\
(\%)\end{array}$ & $\begin{array}{c}\text { Bin } \\
\text { Tane } \\
\text { Ağgırlığı } \\
\text { (g) }\end{array}$ & $\begin{array}{c}\text { Tane } \\
\text { İç } \\
\text { Oranı } \\
(\%)\end{array}$ & $\begin{array}{c}\text { Tane } \\
\text { Nem } \\
\text { Oranı } \\
(\%)\end{array}$ & $\begin{array}{c}\text { Tane } \\
\text { Yağ } \\
\text { Oranı } \\
(\%)\end{array}$ \\
\hline \multirow{3}{*}{ Samsun } & Bafra & & $10.8 \mathrm{~b}$ & $5.3 \mathrm{ab}$ & $3.3 \mathrm{a}$ & $12.7 \mathrm{~b}$ & $65.0 \mathrm{a}$ & $77.5 \mathrm{a}$ & 7.7 & $45.6 \mathrm{~b}$ \\
\hline & Vezirköprü & & $10.7 \mathrm{~b}$ & $5.4 \mathrm{a}$ & $2.9 \mathrm{~b}$ & $19.1 \mathrm{~b}$ & $55.7 \mathrm{c}$ & $68.0 \mathrm{a}$ & 7.0 & $43.2 \mathrm{~d}$ \\
\hline & Havza & & $10.8 \mathrm{~b}$ & $4.9 \mathrm{e}$ & $2.6 \mathrm{c}$ & $14.3 \mathrm{~b}$ & $49.0 \mathrm{e}$ & $75.1 \mathrm{a}$ & 8.0 & $41.6 \mathrm{f}$ \\
\hline Amasya & Merzifon & & $10.6 \mathrm{~b}$ & $5.1 \mathrm{bc}$ & $2.9 \mathrm{~b}$ & $17.2 \mathrm{~b}$ & $57.0 \mathrm{c}$ & $70.6 \mathrm{a}$ & 8.7 & $45.4 \mathrm{c}$ \\
\hline Çorum & Merkez & & $10.6 \mathrm{~b}$ & $5.1 \mathrm{de}$ & $2.9 \mathrm{~b}$ & $26.1 \mathrm{a}$ & $52.7 \mathrm{~d}$ & $58.7 \mathrm{~b}$ & 8.0 & $42.5 \mathrm{e}$ \\
\hline \multirow[t]{2}{*}{ Tokat } & Turhal & & $11.4 \mathrm{a}$ & $4.9 \mathrm{e}$ & $3.0 \mathrm{ab}$ & $18.2 \mathrm{~b}$ & $60.0 \mathrm{~b}$ & $69.4 \mathrm{a}$ & 8.0 & $45.7 \mathrm{a}$ \\
\hline & Ortalama & & 10.8 & 5.1 & 2.9 & 17.9 & 56.6 & 69.9 & 7.9 & 44.0 \\
\hline \multicolumn{2}{|c|}{ Varyans Analaiz } & $s d$ & & & & & & & & \\
\hline Önem & Bölge & 5 & $*$ & $* *$ & $* *$ & $* *$ & $* *$ & $*$ & öd & $* *$ \\
\hline
\end{tabular}

Aynı sütunda değişik harflerle gösterilen ortalamalar arasındaki fark ** \%1 (çok önemli) ve * \%5 (önemli) seviyesinde önemlidir; öd: önemli değil.

Tane boyu, eni ve kalınlı̆̆ı: Karadeniz Bölgesinde yağllk ayçiçeği üreticilerinden temin edilen ayçiçeği tanelerinin, araştırma sonucunda ortalama tane boyu $10.8 \mathrm{~mm}$, eni $5.1 \mathrm{~mm}$ ve kalınlığ $2.9 \mathrm{~mm}$ olmuştur. Üretici bölgelerine göre tane boyu 10.6-11.4 mm, tane eni 4.9-5.4 mm ve tane kalınlığ 2.6-3.3 mm olmuştur. Turhal yöresinde en uzun (11.4 $\mathrm{mm})$, Vezirköprü'de en geniş $(5.4 \mathrm{~mm})$ ve Bafra ilçesinde ise en kalın $(3.3 \mathrm{~mm})$ ayçiçeği tanesi üretimi gerçekleştirilmiştir. Turhal ilçesinde en uzun tane üretilmesine rağmen, tane eni bakımından Havza ilçesi ile birlikte en düşük $(4.9 \mathrm{~mm})$ değer alınmıştır. Tane boyu değerleri, Turhal haricinde diğer yetiştirici bölgelerde birbirine oldukça yakın olmuştur. Konu ile ilgili farklı bölgelerde üretilen yağlık ayçiçeği tohumlarında, tane uzunluğunun $9.52-28.0 \mathrm{~mm}$, tane eninin 4.5-8.3 mm ve tane kalınlı̆̆ının 3.1-3.8 mm arasında değişim gösterdikleri belirtilmiştir (Özgödek, 1993; Bayrak ve Bayraktar, 1995; Gupta ve Das, 1997; Coşge, 2007; Jafari, 2011; Duca ve Glijın, 2013). Araştırma sonucu elde edilen değerler, araştırıcıların belirttikleri değerlere benzerlik göstermiştir.

Kabuk oranı: Ayçiçeği tanesinde kabuk oranının az, tane iç oranının yüksek olması istenen bir özelliktir. Yağlık ayçiçeği tanelerinde belirlenen ortalama kabuk oranı \%17.9 olurken, üretici bölgelerden elde edilen kabuk oranı değerlerinin \%12.7-26.1 arasında değişim gösterdiği belirlenmiştir. Kabuk oranının, Çorum Merkez ilçeden temin edilen örneklerde diğer bölge örneklerine göre daha fazla (\%26.1) olduğu görülmüştür. $\mathrm{Bu}$ bölgeyi $\% 19.7$ ve $\% 18.2$ ile Vezirköprü ve Turhal yöreleri izlerken, Samsun ili Havza ve Bafra ilçelerinde üretimi yapılan yağlık ayçiçeği tanelerinin kabuk oranlarının (\%14.3-12.7) daha düşük olduğu tespit edilmiştir. Kabuk oranı değerlerinin Yazıcıoğlu ve Karaali (1983) \%26-35, Bayrak ve Bayraktar (1995) ise \%21.54-23.32 arasında değiştiğini belirtmişlerdir. Çorum merkezde üretilen ayçiçeği tanelerinin kabuk oranı $(\% 26.1)$ araştırıcıların belirttikleri değerler arasında yer alırken, bölgenin diğer üretici alanlarında belirlenen 
kabuk oranının daha düşük değerlere sahip oldukları belirlenmiştir.

Bin tane ağırlığı: Yağlık ayçiçeği üreticiliğinin yapıldı̆̆ 1 Orta Karadeniz Bölgesi’nde, ayçiçeği tanelerinin ortalama bin tane ağırlığının $56.6 \mathrm{~g}$ olduğu, bölgelere göre tespit edilen bin tane ağırlığının ise 49.9-65.0 $\mathrm{g}$ arasında değişim gösterdiği belirlenmiştir. En fazla bin tane ağırlığ1 Bafra yöresinden temin edilen ayçiçeği tanelerinde (65.0) tespit edilmiş, bunu Turhal (60 g), Merzifon (57.0 g), Vezirköprü (55.7 g) ve Çorum Merkez (52.7 g) yöreleri takip etmiştir. En az ise Havza (49.0 g) bölgesinden temin edilen ayçiçeği örneklerinde ölçülmüştür (Çizelge 1). Araştırma sonucu elde edilen bin tane ağırlığı değerleri, Özgödek (1993), Coşge (2007) ve Seifi ve Alimardani (2010)'nin belirttikleri değerlerden (69.7-183.3 g) düşük Doğan (2010)'ın sonuçlarından (25.43-66.23 g) yüksek olmuş, Kara (1991) ve Demir (2009)'in tespit ettikleri değerler (25.43-66.23 g) arasında yer almıştır.

Tane iç oranı: Tanede iç kısmının yüksek olması istenen önemli bir kalite özelliğidir (Arığlu 1999). Farklı yağlık ayçiçeği üretici alanlarında ortalama \%69.9 oranında tane iç oranı belirlenmiştir. Bölgelere göre \%58.7-77.5 arasında değişen tane iç oranı değerleri bakımından, Bafra (\%77.5), Havza (\%75.1), Merzifon (\%70.6), Turhal (\%69.4) ve Vezirköprü (\%68) bölgelerinde önemli farklılıklar tespit edilmezken, tane iç oranı \%58.7 ile Çorum merkez en düşük değere sahip olmuştur (Çizelge 1). Farklı çalışmalarda tane iç oranı değerlerinin, bölgelere ve araştırmalarda kullanılan ayçiçeği çeşitlerine göre değişiklikler gösterebileceği belirtilmiş olup, tane iç oranının Kara (1991) \%61.971.9, Özgödek (1993) \%46.2-57.0, Karaaslan vd. (2007) \%55.47-74.83 arasında değerler aldığını belirtmişlerdir.

Tane nem oranı: Karadeniz Bölgesinin farklı kesimlerinde üretilen yağlık ayçiçeği tanelerinde belirlenen nem miktarı en fazla Amasya ili Merzifon ilçesinde (\%8.7) olmuştur. Bu bölgeyi \%8'lik nem değerleriyle Havza, Çorum Merkez ve Turhal bölgelerinde yetiştirilen ayçiçeği taneleri takip ederken, Bafra (\%7.7) ve Vezirköprü (\%7)'de en düşük değerler elde edilmiştir (Çizelge 1). Tüm yetiştirici bölgelerde ise ortalama \%7.9 oranında nem tespit edilmiştir. Gupta ve Das (1997) ayçiçeği tanesinde, ortalama \%6.2 olarak daha düşük oranda nem içeriği belirlemişlerdir. Yazıcıoğlu ve Karaali (1983), yağlık ayçiçeği tanelerinin nem oranının \%611, Seifi ve Alimardani (2010) \%4-22, Malik ve Saini (2016) \%7.6-25 arasında değiştiğini bildirmişler, bölgede üretilen ayçiçeği tanelerinde belirlenen nem oranının ise bu değerler arasında yer aldığı saptanmıştır.
Tane yağ oranı: Yağlık ayçiçeği üreticiliğinin yapıldığ 1 bölgelerden temin edilen tanelerin yağ oranlarının \%41.6-45.7 arasında değiştiği, bölgelere göre ortalama yă̆ oranının \%44.0 olduğu belirlenmiştir. Yağ oranı, en fazla Turhal $(\% 45.7)$ ve Bafra (\%45.6); en az Çorum Merkez (\%42.5) ve Havza (\%41.6) yörelerinde üretilen ayçiçeği tanelerinde tespit edilmiştir. Merzifon ve Vezirköprü'de üretilen ayçiçeği tanelerinde yă̆ oranları ise sırasıyla \%45.4 ve 43.2 olmuştur (Çizelge 1). Çiftçi şartlarında yağlık ayçiçeği tohumlarında ortalama $\% 41.30$ oranında yağ içeriği belirlenmişken (Tunçtürk vd. 2005), benzer şekilde ayçiçeği çeşitlerine bağlı olarak yağ içeriklerinin \%46.1-47.6 değiştiği de bildirilmiştir (Çil vd., 2011). Yine, Thavaprakash (2004) \%41.5; Karaaslan vd. (2007) \%39.1-45.9, Kaya (2009) \%38.0-53.4 ve Kara vd. (2013) \%40.40-41.44 arasında olduğunu tespit etmişlerdir.

Araştırma sonucu tanelerde belirlenen özelliklerin, diğer çalışmalara ve Orta Karadeniz Bölgesinde ele alınan üretim alanlarına göre farklılık arz etmesi, kullanılan çeşitlerin özelliğine bağlı olabileceği gibi, iklim ve toprak koşullarındaki ve kültürel uygulamalardaki değişikliklerden etkilenmiş olabilecekleri de söylenebilir. Çevre, toprak ve iklim faktörleri ile çeşitlerin genetik yapısına bağlı olarak tane özelliklerinin değiştiği bir çok araştırmacı tarafından da belirtilmiştir (Bange vd., 1997; İlbaş vd., 1996; Özer vd., 2003; Oraki vd., 2011; Duca ve Glijin, 2013). Ayçiçeği çevre şartlarına karş1 dayanıklı olmasına rağmen iklim faktörleri (sıcaklık ve yağış gibi) özellikle tane gelişme dönemindeki sıcaklık ve güneşlenme süresi yă̆ oranı üzerine önemli etkide bulunduğu gibi (Bange vd.. 1997), yağ oranı bakımından çeşitlerin birbirlerine göre farklılıklar oluşturması, çeşitlerin genetik yapılarının ve ekolojik değişkenlerin farklı olmasından da kaynaklanmaktadır (Önder vd., 2001).

\section{SONUÇ}

Orta Karadeniz Bölgesinin değişik lokasyonlarında yağlık ayçiçeği üreticilerinden temin edilen tanelerin nem oranı haricinde; tane boyu, eni ve kalınlığ 1 , bin tane ağırlığ 1 , tane iç oranı, kabuk oranı, nem ve yağ oranları bakımından önemli farklılıklar tespit edilmiştir. Araştırmanın yürütüldüğü lokasyonlarda yağlık ayçiçeği tanelerinde belirlenen ortalama tane boyu $10.8 \mathrm{~mm}$, eni $5.1 \mathrm{~mm}$, kalınlığ $2.9 \mathrm{~mm}$, kabuk oranı \%17.9, bin tane ağırlığı $56.6 \mathrm{~g}$, tane iç oranı \%69.9, nem içeriği $\% 8.3$ ve yağ oranı \%43.99 olmuştur. Bu sonuçlara göre, bölgede yağlık ayçiçeği üretimi yapılan lokasyonlardan Samsun-Bafra ve TokatTurhal yörelerinden elde edilen yağlık ayçiçeği tanelerinin daha iyi özelliklere sahip oldukları, 
özellikle de yă̆ oranı bakımından daha üstün oldukları belirlenmiştir.

\section{KAYNAKLAR}

Anonim, 2015. 2014 Yılı Ayçiçeği Raporu. Kooperatif̧̧ilik Genel Müdürlüğ̈̈, s:4.

Anonim,$$
2016
$$

Trakya

Birlik. http://slideplayer.biz.tr/slide/7230954/ (01.07.2016)

Anonim, 2016b. http://tr.climate-data.org.

Arıoğlu, H., 1999. Yağ Bitkileri Yetiștirme ve Islahı. Çukurova Üniversitesi Ziraat Fakültesi, Yayın No: 220, S. 175

Arıoğlu, H.H., Kolsarıcı, Ö., Göksu, A.T., Güllüoğlu, L., Arslan, M., Çalışkan, S., Söğüt, T., Kurt, C., Arslanoğlu, F., 2010. Yağ bitkileri üretiminin artırılması olanakları. Türkiye Ziraat Müh. Bir. VII. Teknik Kong. Bildiri Kitab1 I.: 361377. Ankara.

AtakișI, I.K., 1985. Yağ Bitkileri Yetiștirme ve Islahı, Trakya Üniversitesi Ziraat Fakültesi Yayınları, Ders Notu, No:17, Tekirdağ

Bange, M.P., Hammer, G.I.,, Ricket, K.G., 1997. Environmental control of potential yield of sunflower in the tropics. Aust. J. Agric Res. 48: 231- 240

Bayrak, A., Bayraktar, N., 1995. Ayçiçek (Helianthus annuиs L.) yağının yağ asitleri kompozisyonu. GIDA, 20(6): 393-396.

Coşge, B., 2007. Ayçiçeği (Helianthus annuus L.)'nin bazı morfolojik karakterleri ve tohum verimi üzerine metanolün etkisi. Ankara Üniv.Ziraat Fak. Tarım Bilimleri Derg., 13 (3): $246-252$

Çil, A., Çil, A.N., Evci, G., Kıllı, F., 2011. Bazı yağlık ayçiçeği (Helianthus annuus L.) hibridlerinin Cukurova kosullarında bitkisel ve tarımsal özelliklerinin belirlenmesi. Türkiye $I X$. Tarla Bitkileri Kongresi, 12-15 Eylül 2011, S.84, Bursa.

Demir, İ., 2009. Azot ve Kükürdün Ayçiçeğinde (Helianthus annuus L.) Verim ve Verim Ögeleri ile Bazı Kalite Özelliklerine Etkisi. Yayımlanmamış Doktora Tezi. Ankara Ü. Fen Bilimleri Ens., 113 s., Ankara.

Doğan, M., 2010. Sulanmayan Koșullarda Ayçiçeği (Helianthus annuus L.) Çeşitlerinin Tarımsal ve Teknolojik ÖzelliklerininBelirlenmesi Üzerine Bir Araștırma.Yayımlanmamış Yüksek Lisans Tezi, Adana

Duca, M., Glijin, A., 2013. The broomrape effect on some physical and mechanical properties of sunflower seeds. Analele Ştiinţifice ale Universităţii Al. I. Cuza" Iaşis II a. Biologie vegetală, 59, 2: 75-83

Gupta, R.K., Das, S.K., 1997. Physical properties of sunflower seeds. Journal of Agricultural Engineering Research, 66 (1): $1-8$.

Fick, G.N., 1978. Selection for self fertility and oil percentage in development of sunflower hybrid. Proc 8th International Sunflower Conference International Sunflower Associate, pp 418-422, Paris.

İlbas, A.İ., Yıldırım, B., Arslan, B., Dede, Ö., Günel, E., 1996. Van ekolojik koşullarında bazı ayçiçeği (Helianthus annuus L.) Cçeşitlerinin verimi ve önemli tarımsal Oözellikleri üzerinde bir araștırma. Yüzüncü Yıl Üniv. Ziraat Fak. Derg., 6 (3): 189-203.
İncekara, F., 1973. Endüstri Bitkileri ve Islahı. Ege Üniversitesi Matbaası, Cilt: 2, S 75-85, İzmir.

Jafari, S., Khazaei, J., Arabhosseini, A., Massah., J., Khoshtaghaza, M.H., 2011. Study on mechanical properties of sunflower seeds. Food Science and Technology, 14(1): 06.

Kara, K., 1991. Bazı yerli ve yabancı yağlık ayçiçeği (Helianthus annuus L.) çeşitlerini zirai karakterleri üzerine bir araştırma. Ankara Üniversitesi Ziraat Fakültesi Dergisi 1991, 22 (2): S. $62-77$

Kara, K., Öztürk, E., Polat, T., 2013. Farklı yetişme sürelerine sahip yağlık ayçiçeği çeşitlerinin kuru ve sulu koşullarda kışlık (Dondurma) ve yazlık olarak yetiştirilmesi üzerine bir araştırma. Türkiye 10.Tarla Bitkileri Kongresi, 10-13 Eylül, 78-85, Konya.

Karaaslan, D., Tonçer, Ö., Söğüt, T., 2007. Güneydoğu Anadolu Bölgesi koşullarında bazı ayçiçeği (Helianthus annиus L.) çeşitlerinin verim ve bazı verim özellikleri bakımından değerlendirilmesi. Harran Üniv. Zir. Fak. Derg., 11(1/2): 31-38

Malik, M.A., Saini, C.S. 2016. Engineering properties of sunflower seed: Effect of dehulling and moisture content. Cogent Food \& Agriculture, 2(1): 1-11.

Oraki, H., Alahdadi, J., Khajani, F.P., 2011. Sunflower (Helianthus annuus L.) hybrids seeds distribution modelling: Normal, lognormal and weibull models. African Journal of Agricultural Research, 6 (2): 618-62.3

Önder, M., Öztürk, Ö., Ceyhan, E., 2001. Yağlık ayçiçeği çeşitlerinin verim ve bazı verim unsurlarının belirlenmesi. S.Ü. Ziraat Fakültesi Dergisi 15(28):136-146.

Özer, H., Öztürk. E., Polat, T., 2003. Determination of the Agronomic Performances of Some Oilseed Sunflower (Helianthus anпииs L.) Hybrids Grown under Erzurum Ecological Conditions. Turkish Journal of Agriculture and Forestry, 27: 199-2005.

Özgödek, Z., 1993. Erzurum Ekolojik ŞArtlarında YetişTirilen Bazı Çerezlik AyçiçeğI Ekotiplerinin Adaptasyonu Ve Bazı Önemli Tarımsal Özelliklerinin Incelenmesi. Atatürk Üniversitesi, Fen Bilimleri Enstititüsü, Yüksek lisans Tezi, $49 \mathrm{~s}$.

Seifi, M.R., Alimardani, R., 2010. Moisture-dependent physical properties of sunflower seed. Modern Applied Science, 4 (7): 135-143.

Thavaprakash, N., 2004 Effect of nitrogen and phosphorus levels and ratios on yield and quality of sunflower (Helianthus annus L.). Agriculture Science, 24(3): 186-189.

Tunçtürk, M., Eryiğiit, T., Yılmaz, İ., 2005. Van-Erciş koşullarında bazı ayçiçeği (Helianthus annuus $\mathrm{L}$.) ceșitlerinin verim ve verim öğelerinin belirlenmesi üzerine bir araştırma. Türkiye VI. Tarla Bitkileri Kongresi 5-9 Eylül 2005, Antalya.

Yazıcıoğlu, T., Karaali, A., 1983. Türk bitkisel yağlarının yağ asitleri bilesimi. Gebze: Tübitak-M.B.A. Enstitüsü Yayınları, No:70. 